\title{
On the Legitimacy of Intervention
}

\author{
Comment \\ by \\ C. Mantzavinos*
}

My comment on the Legitimacy of Intervention has two interrelated parts. The first part is of a general nature and concerns the problem of the justification of legitimate intervention. The second part will address the main theme of the paper by Frederick Schauer (2014), i.e., the problem of intervention under conditions of epistemic and normative uncertainty. My comment will be based on a philosophical puzzle which is called the Münchhausen Trilemma.

The Baron von Münchhausen was a German nobleman who lived in the 18th century and has become famous as a storyteller. In one of his famous stories he managed to pull himself and the horse on which he was sitting out of a swamp by his own hair. It was the German philosopher Hans Albert who first drew attention to how this story by Münchhausen is analogous to the following situation, which is typical not only of epistemology, but also of ethics and political philosophy.

The search for truth or other values seems to be inseparably tied to the search for secure ground, for an absolute foundation or an ultimate justification. The search for an Archimedean point, the quest for an ultimate justification of values is a manifestation of the vain quest for certainty originating in the idea of a positive, sufficient justification. This general philosophical idea, operative both in epistemology and philosophy of science as well as in ethics and political philosophy, mandates the quest for an adequate foundation, a sufficient justification, for all convictions and principles. The demand for a justification of everything leads to a situation with three alternatives, all of which are unacceptable: the Münchhausen Trilemma, named such because of the analogy existing between this problem and one which that baron once had to solve in the story mentioned above. It is a situation characterized by three alternatives, all of them seemingly unacceptable or in other words a trilemma.

"One must choose [...] between

(1) an infinite regress, which seems to arise from the necessity to go further and further back in the search for foundations, and which, since it is in practice impossible, affords no secure basis;

* University of Athens, Department of Philosophy and History of Science.

Journal of Institutional and Theoretical Economics - ISSN 0932-4569

DOI: 10.1628/093245614⿴囗十 - (c) 2014 Mohr Siebeck 
(2) a logical circle in the deduction, which arises because, in the process of justification, statements are used which were characterized before as in need of foundation, so that they can provide no secure basis; and finally

(3) the breaking-off of the process at a particular point, which, admittedly, can always be done in principle, but involves an arbitrary suspension of the principle of sufficient justification.

Since both an infinite regress and a circular argument seem clearly unacceptable, one is inclined to accept the third possibility, for the simple reason that no other way out of the situation is thought to be possible. Of statements where one is prepared to break off the foundation process, it is customary to use words such as 'selfevident,' 'self-authenticating,' 'based upon immediate knowledge' - upon intuition or experience that is - or in some other way to render palatable the fact that one is prepared to break off the foundation regress at some particular point and suspend the foundation postulate with respect to this point, declaring it to be an Archimedian point (of knowledge). [...] If such a conviction or statement is called a dogma, then our third possibility is revealed as something one would have least expected in a solution to the foundation problem: justification by recourse to a dogma." (Albert, 1985, pp. 18f).

Such dogmatism, and the Münchhausen Trilemma more generally can be avoided by substituting the principle of critical examination for the principle of sufficient justification. In accord with this principle, a discussion of the problems of epistemology, philosophy of science, or ethics need not refer back to ultimate reasons in order to be convincing or "rational." Instead, problems that arise in the sphere of cognition or in the sphere of praxis are to be discussed and solved in light of the already existing solutions. Solutions to new types of problems of any sort require creativity and imagination and are not worked out in a social and mental vacuum. The application of the principle of critical examination means that solutions are to be creatively discovered, they are to be weighed in reference to certain values and standards, and, on this basis, the preferred solutions to problems are to be decided upon. Solutions are not judged to be good or rational by virtue of being based on certain knowledge or ultimate values. Instead, our solutions in all areas of cognition and action are fallible, but they can be improved by critical discussion.

Though not all discussions can be found guilty of committing the crime, so to say, of a quest for ultimate justification - they simply ask for justification without assuming that this should be final - the quest for ultimate foundations still remains implicitly given. It is, thus, important to stress that to the question posed in the symposium: "What makes intervention legitimate?" the only sensible answer is: "Nothing", if the question is supposed to have a satisfactory answer only in the case of the provision of an ultimate justification for legitimacy.

Now let me come to my more specific comment on the paper of Frederick Schauer, which is also tied to the Münchhausen Trilemma. The central theme of Schauer's paper, very nicely encapsulated in the opening phrase of his contribution, is that "Decisions about intervention are decisions made under conditions of uncertainty" 
(Schauer, 2014, section 1). As he himself claims "The goal of this paper is to examine the question of intervention in light of the fact that decisions to intervene and decisions not to intervene may each turn out to have been the wrong decision" (section 1). In a sense, thus, the general framework within which his arguments unfold is a fallibilistic framework. This is perfectly clear, I think, with respect to what Schauer propitiously calls epistemic uncertainty. ${ }^{1}$ His proposal to deal with the pervasive epistemic uncertainty is by means of following what he calls the principle of epistemic modesty, and his arguments for introducing such a principle are very convincing indeed.

However, Schauer excludes from his analysis the possibility of normative uncertainty, i.e. "uncertainty about the very reasons to intervene, as opposed to uncertainty about the existence of triggering facts [...] under an accepted or internalized reason to intervene" (section 8). This seems to me to be a serious shortcoming. As he modestly states in the last paragraph of his paper, he characterizes his own project more "as a prolegomenon to a model of tolerance and intolerance, or intervention and non-intervention" (section 8) rather than as a full model. Insofar it is not fair to expect that normative uncertainty is also paid full attention in this prolegomenon. However, I think that fallibilism can and should also be easily extended to include normative claims; articulating them at greater length would make the project an even more successful one. So, let me close this short comment by giving the general flavor of a fallibilistic position.

Fallibilism is the position that all our knowledge, activities, principles, positions, and rules are prone to error. In all areas of cognition and action, human beings constantly make mistakes, but they are able to learn from them. A fallibilist treats all problem solutions as hypothetical: he provisionally accepts them instead of searching for a final justification for them. The fallibilistic attitude can be applied to all areas of human activity: science, politics, and even religion. (The existence of God can be treated as a hypothetical postulate to be critically discussed, for example.) In a nutshell, fallibilism is so productive because it treats all criteria and values as hypotheses amenable to criticism and revisions - possibly progressive ones.

\section{References}

Albert, H. (1985), Treatise on Critical Reason, Princeton University Press, Princeton (NJ). Mantzavinos, C. (2001), Individuals, Institutions, and Markets, Cambridge University Press, Cambridge.

- , D. C. North, and S. Shariq (2004), "Learning, Institutions, and Economic Performance," Perspectives on Politics, 2(1), 75-84.

\footnotetext{
${ }^{1}$ Epistemic uncertainty is, of course, a main reason for the very existence of institutions. See Mantzavinos (2001) and Mantzavinos, North, and Shariq (2004).
} 
Schauer, F. (2014), “Modeling Tolerance," Journal of Institutional and Theoretical Economics (JITE), 170(1), forthcoming.

C. Mantzavinos

Department of Philosophy

and History of Science

University of Athens

University Campus

15771 Athens

Greece

cmantzavinos@phs.uoa.gr 